
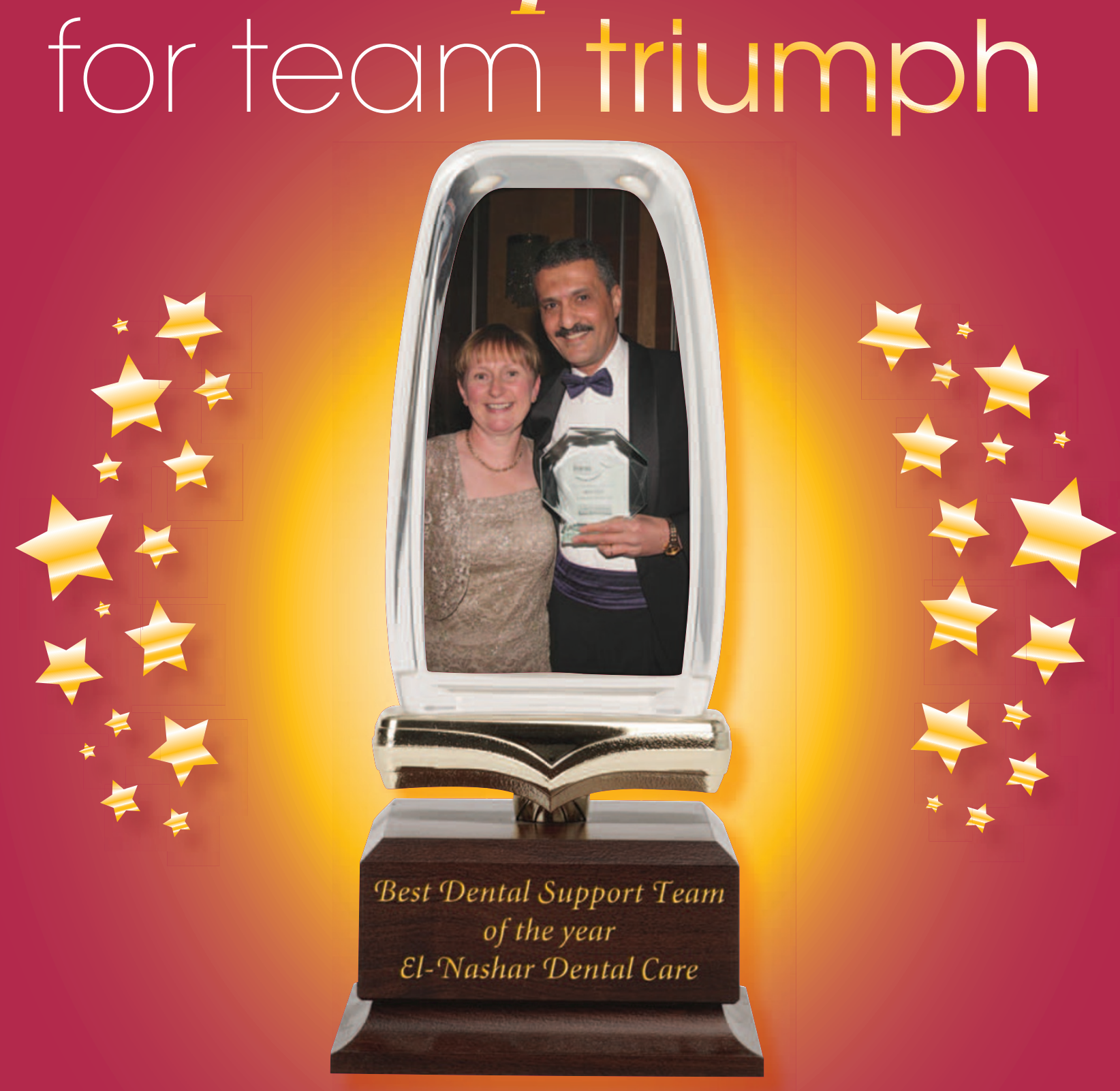

How does a dental practice with six surgeries and 22 staff function smoothly and maintain motivation as a team? Julie Ferry spoke to award-winning El-Nashar Dental Care in Devon.

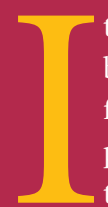

$\mathrm{t}$ was a moment the whole team had been waiting for. Dressed in their finest, they had travelled from the practice in Newton Abbot, Devon to the Lancaster Gate Hotel in central London to hear the verdict and now it was in. The prestigious Probe award for the Best Dental Support Team of the year was announced and they had done it - El-Nashar
Dental Care had won.

Speaking to practice manager, Sharon ElNashar, 48, a few months later it is clear that it was a night she will always remember.

'The award was the icing on the cake of a brilliant year for the practice,' she says. 'We were just so proud of the whole team and pleased that we were all recognised for our work in such a nice way. I think it has taken each team member up another level of motivation and we are determined to keep up the good work.'

Practice supervisor, Cherry Young, 64, who has been with the practice for seven years, agrees: 'Receiving a team award means that everyone shared the occasion, however the award also felt like a real personal achievement - it makes you realise that all 


\section{day in the life}

the effort you put into your job is worth it.'

The practice has certainly been through its fair share of changes in the last few years. Sharon and practice principal and husband, Hassan first opened for business nine years ago when they set-up as a single-handed practice, sharing costs with another dentist in the same building. However, it wasn't long before patient demand meant that the couple were looking to expand. First they took on an associate and then a few years later they opened another practice just down the road when the PCT asked them to run some contracts. Therefore, they had three chairs in the new practice while still keeping the two chairs at the cost-sharing practice.

'We ran the business like that for two years', says Sharon. 'However, pretty quickly we realised that the new practice was becoming such a great success because we had more control over it. We talked it over with the team at one of our team days and the general consensus was that we should find a building where we could all be on one site. After lots of searching we opened a whole new practice in May this year. We now have one big practice with six surgeries and 22 staff.'

Such rapid expansion was bound to have an effect on team members, but as the award reveals, the transition from small to big team was handled smoothly by all involved. One of the reasons for this may have been Sharon's business background. When the practice was first established Sharon ran her own and so she eventually gave up her own business.

'I love being a practice manager and the best thing about it is that all of the skills I have learnt through working with other organisations I have been able to use here. Helpfully, management communications is a pretty generic

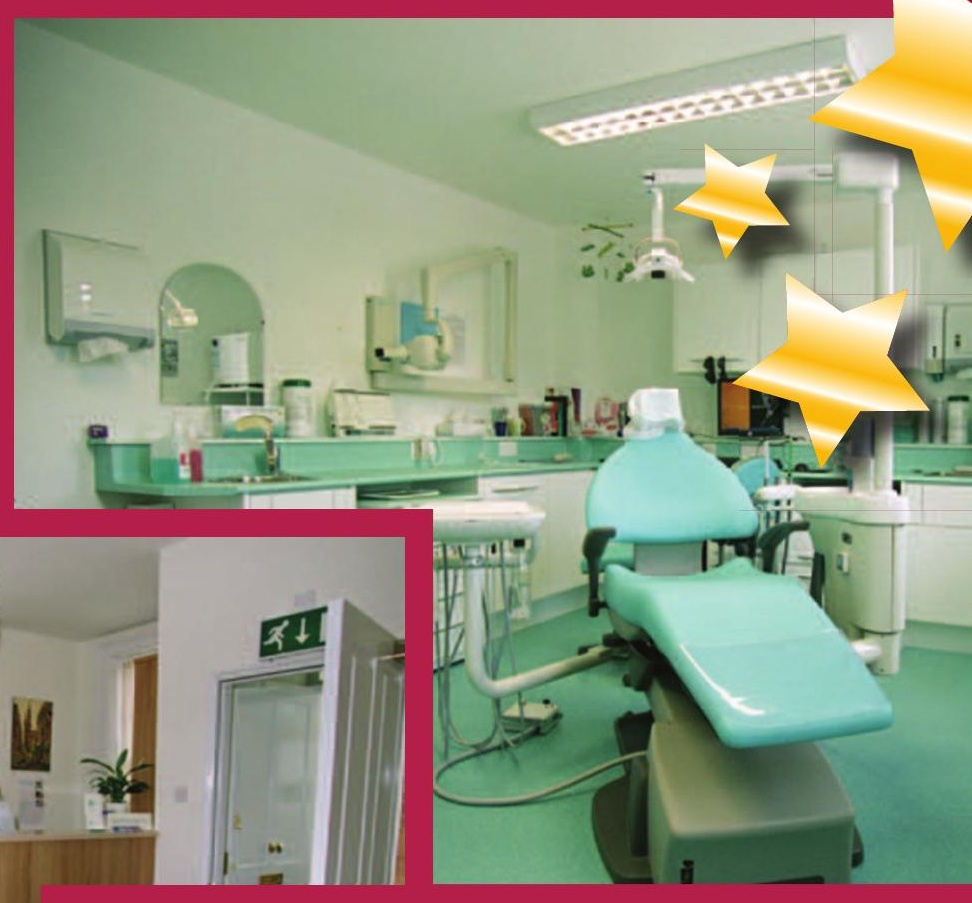

(1)

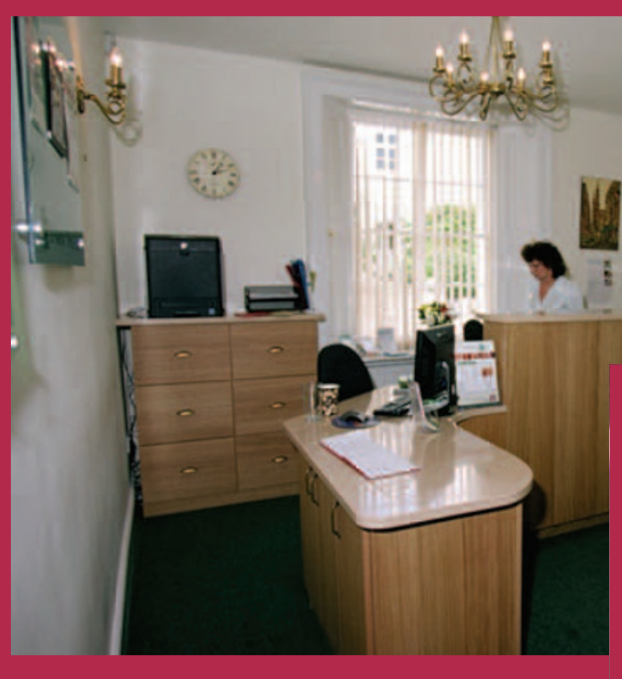

subject, so it can be applied to lots of different businesses. Also, because I don't come from a dental background I could look at the practice from a totally different perspective, which has been very beneficial.'

When asked what she thinks makes the dental team at ElNashar so special, Sharon doesn't hesitate. 'Communication,' she says. 'There is a lot of respect for the dentists here

\section{'The award has taken each team}

\section{member up another level of}

\section{motivation and we are determined to}

\section{keep up the good work.'}

management training business and was only on practice manager duties during the evenings and weekends. However, as the practice grew it became clear that she would have to take on more of a role in the practice's affairs but the rest of the dental team aren't afraid to talk to them and give constant feedback. Every month we have a breakfast staff meeting from 8.30-10am where we have cookies and croissants and talk over any issues affecting the practice. We also have three team days a year and every November we have our main team day where we sit down and write the business objectives for the next 12 months. Suggestions last year included getting more involved with recycling at the practice, doing charity events like a sponsored walk - which we are doing next week - and a reward scheme for children if they come in for two check-ups in a row and don't need anything done. These are the softer business objectives running alongside the harder business objectives like marketing - mix them together and they all work really well.'

Cherry Young, who has worked in dentistry since she was 18 , likes the fact that her ideas are listened to at the practice and 
